\title{
Direct Immunosensor Design Based on the Electrochemical Reduction of 4-((4-Nitrophenyl)ethynyl)benzenethiol Monolayers
}

\author{
Dwight A. Williams, ${ }^{1}$ Wraegen A. M. Williams, ${ }^{2}$ Melissa C. Rhoten, ${ }^{3}$ \\ Charlene D. Crawley, ${ }^{4}$ and Suzanne Ruder ${ }^{4}$ \\ ${ }^{1}$ School of Science, Lynchburg College, Lynchburg, VA 24501-3113, USA \\ ${ }^{2}$ School of Engineering and Applied Science, University of Virginia, Charlottesville, VA 22904-1000, USA \\ ${ }^{3}$ Department of Chemistry and Physics, Longwood University, Farmville, VA 239093-1801, USA \\ ${ }^{4}$ Department of Chemistry, Virginia Commonwealth University, Richmond, VA 23284-2006, USA
}

Correspondence should be addressed to Charlene D. Crawley, cdcrawle@vcu.edu

Received 25 May 2011; Accepted 13 August 2011

Academic Editor: Ignacio Matias

Copyright (C) 2011 Dwight A. Williams et al. This is an open access article distributed under the Creative Commons Attribution License, which permits unrestricted use, distribution, and reproduction in any medium, provided the original work is properly cited.

The synthesis and characterization of novel $\mathrm{N}$-arylhydroxylamine-based molecular wires are described for use in the site-directed covalent immobilization of whole IgG antibodies onto gold electrode surfaces. The hydroxylamine, electrochemically generated in situ from reduction of the corresponding nitrobenzene, is stable under a wide range of solution conditions and reacts selectively with carbohydrate away from the antibody-binding site to allow the development of immunosensors with maximal activity. Cyclic voltammetric responses have shown a direct correlation between the structure and length of the molecular wire and its stability and concentration at the electrode surface.

\section{Introduction}

Over the past decade, the development of devices that can rapidly, accurately, and reproducibly detect specific analytes in complex mixtures has been the focus of many research groups [1-5]. Of particular interest is the development of immunosensors that are capable of detecting low molecular weight $(<500$ Daltons) analytes such as pesticides at trace levels $[4,6-8]$. The response of these immunosensor devices results from interactions between an antibody $(\mathrm{Ab})$ and its corresponding antigen $(\mathrm{Ag})$.

Catt et al. first reported the immobilization of antibodies onto solid supports for sensor applications in 1967 [9]. Since this time, physical adsorption and covalent immobilization have evolved as the two major approaches towards Ab immobilization. Of these two approaches, covalent attachment of the $\mathrm{Ab}$ via a nonsite directed or site-directed approach has gained much attention. With site-directed attachment, a specific region of the $\mathrm{Ab}$ is targeted $[10,11]$. This region is preferably located away from the Ag binding sites leaving them free to interact with the antigen of interest. Within the lower portion of the globular protein structure of the $\mathrm{Ab}$, there is a small number of carbohydrate residues known as the Fc region [12]. For immunosensor development, this carbohydrate region has become increasingly important and has opened new avenues for $\mathrm{Ab}$ surface immobilization strategies [13-16]. The carbohydrate residues of the Fc region are oxidized with periodate to give aldehydes [17], which can then be reacted with a number of functional groups to covalently bind the $\mathrm{Ab}$ to the surface [18-20]. Typically, amines, hydrazines, and hydrazides are used to immobilize the oxidized Ab. Although these functionalities result in the covalent attachment of Ab to the surface, the use of amines requires the addition of sodium cyanoborohydride upon condensation to reduce the Schiff base to a stable structure. The need for this additional reagent leads to decreases in Ab-binding activity; therefore, decreasing the amount of Ag that can be detected. Hydrazine and hydrazides 
have also been used for $\mathrm{Ab}$ immobilization, but these moieties required harsh reaction conditions for formation. Although this has no effect on the Ab structure, it can cause significant challenges when seeking to synthesize novel Ab immobilizing agents.

There is a need for immunosensor surfaces that are capable of directly detecting Ab-Ag interactions. Due to the lack of ease when incorporating amines, hydrazines, and hydrazides into thiol surfaces, the broad scope objectives of this research are to investigate new functional groups that can readily form covalent bonds to whole IgG antibody $(\mathrm{Ab})$ that are ultimately bound onto gold electrode surfaces. General representations of the molecular wire targets used in this study are shown in Figure 1. The terminal hydroxylamine functionality can react with the oxidized carbohydrate region of the $\mathrm{Ab}$ to form a covalent bond, while terminal thiol forms a bond at the electrode surface. The exhaustive number of studies on the self-assembly of thiols at gold surfaces and the large number of literature reports using SAM-modified electrodes in immunosensor development made this functional group a logical choice [21-24]. NArylhydroxylamines have not previously been used for $\mathrm{Ab}$ immobilization and would be a new addition to the family of functional groups typically used for $\mathrm{Ab}$ immobilization. The advantages to using $\mathrm{N}$-arylhydroxylamines over the more commonly used succinimide esters and hydrazides are synthetically motivated. N-Arylhydroxylamines are best formed via the reduction of nitrobenzenes. Nitrobenzene derivatives are widely available, relatively inexpensive, and stable under a wide range of reaction conditions under which the more traditional $\mathrm{Ab}$ immobilizing functional groups (succinimide ester and hydrazides) would be incompatible.

A number of methods have been developed to reduce nitrobenzene to an $\mathrm{N}$-arylhydroxlamine derivative [25-32]. We specifically looked to the electrochemical reduction of the nitro functional group [32]. Tsutsumi and Kolb have shown that SAMs of 4-nitrothiolphenol (4-NTP) can be readily reduced while maintaining the integrity of the monolayer $[33,34]$. We sought to use this methodology to reduce monolayers of our molecular wires to their $\mathrm{N}$-arylhydroxylamines and then covalently bind $\mathrm{Ab}$ to the modified electrode surface through condensation with aldehydes present within the Ab.

\section{Materials and Methods}

All synthetic reactions were carried out under a nitrogen atmosphere. All chemicals and solvents were purchased from Aldrich, TCI, and VWR and used as received unless otherwise noted. Tetrahydrofuran (THF) was freshly distilled from $\mathrm{Na}^{0}$ and benzophenone. Dimethylformamide (DMF) was stirred over $\mathrm{CaH}_{2}(5 \% \mathrm{w} / \mathrm{v})$ overnight, filtered, and then distilled under vacuum. The freshly distilled DMF was stored over $3 \AA$ ' molecular sieves. Celite 521 was purchased from Aldrich. Chromatography was performed using 230400 mesh silica purchased from EMD science (VWR). Thinlayer chromatography was performed on Silica gel $60 \mathrm{~F}_{254}$ silica-coated alumina plates and visualized by UV and iodine.

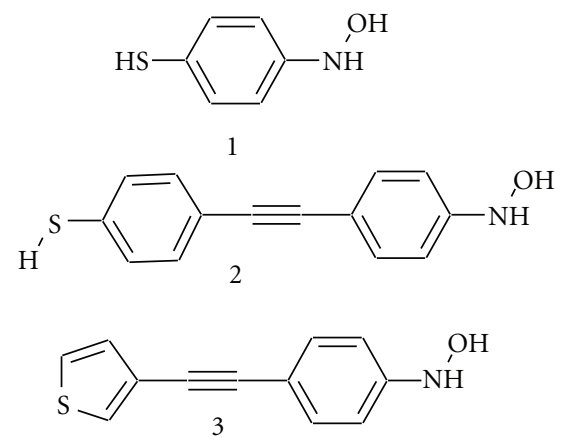

Figure 1: Molecular wire targets.

2.1. Instrumentation. ${ }^{1} \mathrm{H}$ NMR spectra were recorded on a Varian AS400 instrument operating at $400.130 \mathrm{MHz}$ or a Varian Mercury instrument operating at $299.865 \mathrm{MHz}$. Chemical shifts are reported in ppm relative to the residual protonated solvent peak. ${ }^{13} \mathrm{C}$ NMR spectra were recorded on a $75.408 \mathrm{MHz}$ instrument, and chemical shift values are reported in ppm relative to the solvent peak. Cyclic voltammetry was carried out on a $\mathrm{CH}$ Instrument $430 \mathrm{~A}$ (CH Instruments, Inc., Austin, Tex, USA). All analyses were performed on gold Quartz Crystal Microbalance (QCM) electrodes $(10 \mathrm{MHz})$ that were purchased from International Crystal Manufacturing Co., Inc. (Part no. $=131215-10$ Blank Diameter $=0.538^{\prime \prime}$ Frequency $=10.000 \mathrm{MHz}$ Surface Finish $=$ Polish Electrode Diameter $=0.201^{\prime \prime}$ Electrode Material $=100 \AA \mathrm{Cr}$ and $1000 \AA$ Au Mounted and Bonded). All experiments were performed in a three electrode Teflon QCM cell ( $\mathrm{CH}$ Instruments, Inc., Austin, Tex, USA). The auxiliary electrode was a platinum wire and the reference electrode was a double junction $\mathrm{Ag} / \mathrm{AgCl}$ with $1 \mathrm{M} \mathrm{KCl}$ in the inner chamber and phosphate buffer at the same concentration used in the analysis in the outer chamber.

\subsection{Synthesis}

2.2.1. 4-((4-Nitrophenyl)ethynyl) benzenethiol (2) (4-NEB). 1 -Ethynyl-4-nitrobenzene $(0.529 \mathrm{~g}, 3.598 \mathrm{mmol})$, 4-iodobenzenethioacetate $(0.971 \mathrm{~g}, 3.493 \mathrm{mmol}), \mathrm{PdCl} 2(\mathrm{PPh} 3) 2$ (0.044 g, $0.048 \mathrm{mmol})$, CuI (0.037, $0.198 \mathrm{mmol})$, and THF : DIA $(1: 1)$ were mixed at $50^{\circ} \mathrm{C}$ for $24 \mathrm{~h}$. The crude mixture was then concentrated and S-4-((4-nitrophenyl)ethynyl)phenyl ethanethioate was isolated by chromatography using $\operatorname{DCM}(0.799 \mathrm{~g}, 75 \%$ yield $) .1 \mathrm{H} \mathrm{NMR}(300 \mathrm{MHz}, \mathrm{CDCl} 3) \delta=$ $8.23(\mathrm{~d}, 2 \mathrm{H}, J=9.0 \mathrm{~Hz}, \mathrm{ArH}), 7.65(\mathrm{~d}, 2 \mathrm{H}, J=9.0 \mathrm{~Hz}, \mathrm{ArH})$, 7.57 (d, 2H, J = 9.0 Hz, ArH), 7.13 (d, 2H, J = 9.0 Hz, ArH), 2.32 (s, 3H, S(O)CH3); 13C NMR (75.4 MHz, CDCl3) $\delta=$ $193.5,147.4,134.5,133.6,132.6,132.5,130.0,129.5,123.9$, 123.8 , and 123.4 .

To S-4-((4-nitrophenyl)ethynyl)-phenyl ethanethioate $(0.045 \mathrm{~g}, 0.163 \mathrm{mmol})$ dissolved in DMSO was added $\mathrm{KOH}$ $(3 \mathrm{M}, 0.326 \mathrm{mmol})$. After $1 \mathrm{~h}$ the reaction was complete and the reaction mixture was acidified with $\mathrm{HCl}$. The aqueous layer was extracted with DCM, washed with water, dried, and concentrated to yield a yellow solid $(0.036 \mathrm{~g}, 87.3 \%$ yield $) .{ }^{1} \mathrm{H}$ $\operatorname{NMR}\left(300 \mathrm{MHz}, \mathrm{CDCl}_{3}\right) \delta=8.22(\mathrm{~d}, 2 \mathrm{H}, J=9.0 \mathrm{~Hz}, \mathrm{ArH})$, 
$7.65(\mathrm{~d}, 2 \mathrm{H}, J=9.0 \mathrm{~Hz}, \mathrm{ArH}), 7.42(\mathrm{~d}, 2 \mathrm{H}, J=9.0 \mathrm{~Hz}, \mathrm{ArH})$, and $7.27(\mathrm{~d}, 2 \mathrm{H}, J=9.0 \mathrm{~Hz}, \mathrm{ArH})$.

2.2.2. 3-((4-Nitrophenyl)ethynyl)thiophene (3) (3-NET). To synthesize the necessary acetylene 1-bromo-4-nitrobenzene $(2.06 \mathrm{~g}, 10.25 \mathrm{mmol})$, trimethylsilyacetylene $(1.18 \mathrm{~mL}, 8.349$ $\mathrm{mmol}$ ) and TEA were mixed at room temperature. To this mixture, $\mathrm{PdCl}_{2}\left(\mathrm{PPh}_{3}\right)_{2}(0.14 \mathrm{~g}, 0.199 \mathrm{mmol})$ and $\mathrm{CuI}(0.01 \mathrm{~g}$, $0.053 \mathrm{mmol}$ ) were added. The reaction continued to stir at $\mathrm{rt}$ for $4 \mathrm{~h}$. After this time, the reaction mixture was concentrated and the crude material was purified by column chromatography using DCM to give trimethyl((4nitrophenyl)ethynyl)silane (2.237 g, $99.6 \%$ yield). ${ }^{1} \mathrm{H}$ NMR $\left(300 \mathrm{MHz}, \mathrm{CDCl}_{3}\right) \delta=8.15(\mathrm{~d}, 2 \mathrm{H}, J=9.0 \mathrm{~Hz}, \mathrm{ArH}), 7.64$ $(\mathrm{d}, 2 \mathrm{H}, J=9.0 \mathrm{~Hz}, \mathrm{ArH})$, and $0.174\left(\mathrm{~s}, 9 \mathrm{H},\left(\mathrm{CH}_{3}\right)_{3}-\mathrm{C}\right)$.

To trimethyl((4-nitrophenyl)ethynyl)silane $(2.237 \mathrm{~g}, 10.2$ $\mathrm{mmol}$ ) and $\mathrm{K}_{2} \mathrm{CO}_{3}(0.085 \mathrm{~g}, 0.611 \mathrm{mmol})$ was added $\mathrm{MeOH}$ $(43 \mathrm{~mL})$ and the reaction was stirred at $\mathrm{rt}$ for $2 \mathrm{~h}$. The resulting mixture was concentrated at room temperature and the resulting residue was dissolved in $\mathrm{CH}_{2} \mathrm{Cl}_{2}(40 \mathrm{~mL})$. The organic layer was washed with saturated $\mathrm{NaHCO}_{3}(2 \times$ $20 \mathrm{~mL})$ and water $(2 \times 20 \mathrm{~mL})$. After drying over $\mathrm{MgSO}_{4}$ and concentrating a black solid resulted. The crude material was purified on silica gel using $\mathrm{CH}_{2} \mathrm{Cl}_{2}$ to give 1-ethynyl4-nitrobenzene as an orange solid $(1.246 \mathrm{~g}, 83 \%$ yield $) .{ }^{1} \mathrm{H}$ NMR $\left(300 \mathrm{MHz}\right.$, Acetone- $\left.\mathrm{d}_{6}\right) \delta=8.20(\mathrm{~d}, 2 \mathrm{H}, J=8.7 \mathrm{~Hz}$, $\mathrm{ArH}), 7.63(\mathrm{~d}, 2 \mathrm{H}, J=9.0 \mathrm{~Hz}, \mathrm{ArH}), 3.35(\mathrm{~s}, 1 \mathrm{H}, \mathrm{H}-\mathrm{C} \equiv \mathrm{C})$; ${ }^{13} \mathrm{C}$ NMR $\left(75.4 \mathrm{MHz}, \mathrm{CDCl}_{3}\right) \delta=133.2,129.1,123.8,82.5$, and 81.8 .

To a mixture of 3-iodothiophene $(0.207 \mathrm{~g}, 0.984 \mathrm{mmol})$, $\mathrm{PdCl}_{2}\left(\mathrm{PPh}_{3}\right)_{2} \quad(0.014 \mathrm{~g}, 0.019 \mathrm{mmol}), \quad \mathrm{CuI}(0.004 \mathrm{~g}, \quad 0.019$ $\mathrm{mmol})$, and 1-ethynyl-4-nitrobenzene $(0.145 \mathrm{~g}, 0.984 \mathrm{mmol})$ was added THF. DIA was added to the above mixture and the reaction was stirred overnight at rt. The resulting mixture was concentrated under reduced pressure and purified by column chromatography using $\mathrm{CH}_{2} \mathrm{Cl}_{2}$ to give 3 as a yellow solid. ( $0.199 \mathrm{~g}, 88.3 \%$ yield). ${ }^{1} \mathrm{H}$ NMR $(300 \mathrm{MHz}$, Acetone- $\left.\mathrm{d}_{6}\right) \delta=8.28(\mathrm{~d}, 2 \mathrm{H}, J=9.0 \mathrm{~Hz}, \mathrm{ArH}), 7.89(\mathrm{dd}$, $1 \mathrm{H}, J=3.0,1.2 \mathrm{~Hz}, \mathrm{HC}=\mathrm{CH}-\mathrm{S}), 7.80(\mathrm{~d}, 2 \mathrm{H}, J=9.0 \mathrm{~Hz}$, ArH), $7.61(\mathrm{dd}, 1 \mathrm{H}, J=5.1,3.0 \mathrm{~Hz},=\mathrm{CH}-\mathrm{S}), 7.30(\mathrm{dd}, 1 \mathrm{H}$, $J=5.1,1.2 \mathrm{~Hz},=\mathrm{CH}-\mathrm{S}) ;{ }^{13} \mathrm{C}$ NMR $\left(75.4 \mathrm{MHz}, \mathrm{DMSO}-\mathrm{d}_{6}\right)$ $\delta=142.9,141.3,140.5,140.2,137.2,134.3,131.6,100.2$, and 97.4.

2.3. Electrode Preparation Protocol. The electrode was first dipped in a piranha solution $\left(3: 2 \quad \mathrm{H}_{2} \mathrm{SO}_{4}: \mathrm{H}_{2} \mathrm{O}_{2}\right)$ for 60 seconds. Following the piranha dip the electrode was rinsed with $18 \mathrm{M} \Omega$ deionized Milli-Q water and sonicated in both water (Milli-Q) and ethanol for 15 minutes each. The electrode was then cleaned in a UV chamber for 60 minutes, rinsed with water (Milli-Q) and ethanol, then blown dry with ultrapure nitrogen. The electrode was then electrochemically cleaned using cyclic voltammetry (0 to $-950 \mathrm{mV}$ versus $\mathrm{Ag} / \mathrm{AgCl} 1 \mathrm{M} \mathrm{KCl}$ ) in a $10 \mathrm{mM} \mathrm{H}_{2} \mathrm{SO}_{4}$ solution, rinsed with water and blown dry with ultrapure nitrogen. Following this a $50 \mathrm{mM}$ solution of 4 -NTP in dichloromethane (DCM) was placed on the gold electrode for 24 hours to allow for monolayer formation. In the case of $\mathbf{3}$, monolayer formation was allowed to proceed for 72 hours. The electrode was then rinsed with DCM and hexanes. Following this the electrode was immersed in a solution of $0.1 \mathrm{M}$ sodium phosphate buffer at $\mathrm{pH}$ 7. Cyclic voltammetry was carried out using a standard three-electrode design, where the SAM modified electrode served as the working electrode. The reference electrode was a commercially purchased $\mathrm{Ag} / \mathrm{AgCl}$ electrode in $1 \mathrm{M} \mathrm{KCl}$ and a commercial platinum wire was used as the auxillary.

\section{Results and Discussion}

Though the electrochemical reduction of electrodes modified with a SAM of 4-NTP have been carried out by others $[33,34]$, for this application there were two critical questions that had to be answered: (a) what is the maximum concentration of hydroxylamine that can be produced at the surface and (b) can the long-term stability of the freshly formed hydroxylamine monolayer be improved? The stability of the hydroxylamine over time is important, because previous literature has shown that the condensation with the $\mathrm{Ab}$ is expected to take a minimum of 8 hours [35]. In Kolb's report it was noted that $\mathrm{pH}$ of the reducing media had an impact on the maximum current response (which can be related to concentration of hydroxylamine at the surface) that was observed. However, there were no comments with regards to improving the long-term stability of the hydroxylamine [34]. In the reports of Tsutsumi, on the other hand, it was stated that a clear response of the redox pair could be seen with repetitive cycles if the potential limits were selected carefully [33]. However, in these reports the reduction was carried out under acidic conditions. These conditions were noted by Kolb to lower the maximum observed current response [34].

To answer these aforementioned questions, CV experiments were carried out and the results are shown in Figures 2 and 3. In both figures, a fresh 4-NTP modified electrode was prepared and the potential was poised at $-400 \mathrm{mV}$ for 15 minutes. This serves to reduce the 4-NTP to the hydroxylamine. This was followed by a CV scan between the potential limits of -400 and $0 \mathrm{mV}$. The signal observed in this potential window is due to the oxidation of the hydroxylamine to the corresponding nitroso compound followed by rereduction to the hydroxylamine. Figure 2 shows the time dependence of the hydroxylamine/nitroso redox couple. Trace A shows the current response for the redox couple after the electrode was poised at $-400 \mathrm{mV}$ for 15 minutes and then scanned between -400 and $0 \mathrm{mV}$. Upon completion of each CV the electrode was repoised at $-400 \mathrm{mV}$ for a second 15 minute interval and then scanned between -400 and $0 \mathrm{mV}$. This process was repeated every 15 min over a 6 hour period to give traces $\mathrm{C}-\mathrm{H}$.

It was hoped that the current response would increase plateau and remain constant with repetitive cycles once the maximum concentration of hydroxylamine was obtained at the surface. However, unlike the reports of Tsutumi, the current response only increased over the first $30 \mathrm{~min}$ and then rapidly decayed. To better understand what was occurring, a second experiment was undertaken, where the reducing potential was applied only for $30 \mathrm{~min}$ (the time 


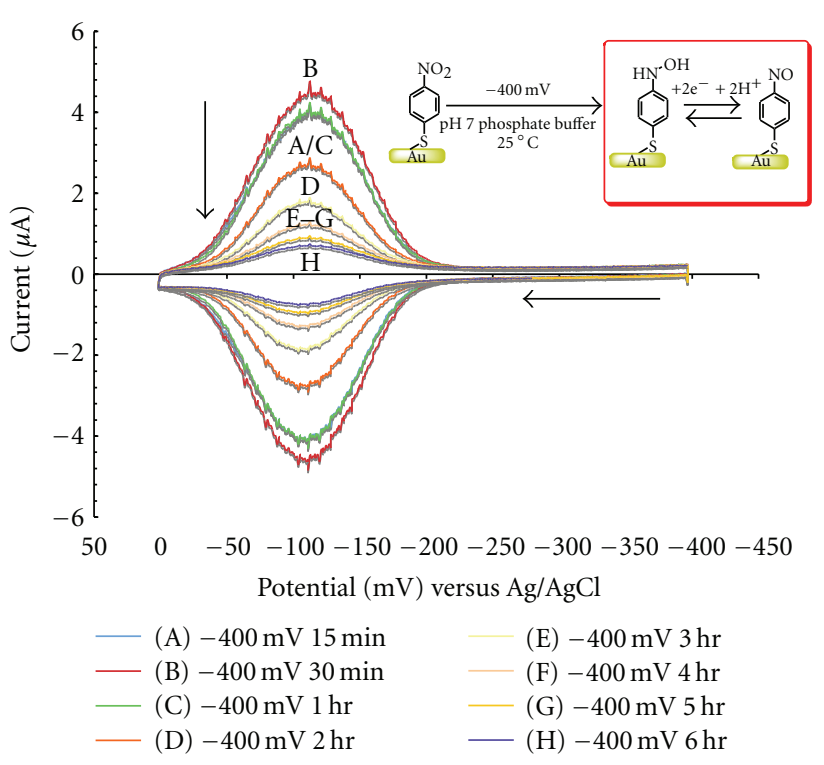

FIGURE 2: Electrochemical reduction of 4-NTP over 6 hours.

noted for maximum current response) and the electrode was scanned and then allowed to return to the open circuit potential.

CVs were taken every 15 min over a $5.5 \mathrm{~h}$ period after the initial scan. It should be noted that the reducing potential of $-400 \mathrm{mV}$ was only applied at the start of this experiment (i.e., the electrode was not held at this potential prior to each additional scan). Figure 3 shows the CV scans taken. It also shows that in the absence of an applied potential the current decreases quite rapidly prior to each additional scan. At the end of this series of $\mathrm{CV}$, the reducing potential $(-400 \mathrm{mV})$ was applied for $30 \mathrm{~min}$ (trace $\mathrm{F})$. The current response obtained here is also dramatically lower than that of the original trace, A. This points strongly to the fact that an irreversible process is occurring at the surface. We envisioned three possible explanations for this observed decrease in current response. The first is the complete and irreversible reduction of the monolayer to the amine. The second is desorption of the monolayer from the electrode, and the third involved cross-coupling of the nitroso intermediate with a neighboring hydroxylamine to generate an unwanted azoxy compound. This was surprising as crosscoupling between hydroxylamines and nitroso intermediates is expected to occur under slightly alkaline conditions $(\mathrm{Ph}=$ 8). Two factors may allow this reaction to proceed under our experimental conditions: (1) the close proximity of the hydroxylamine and nitroso compound intermediates to the surface and (2) the electron donating ability of sulfur is expected to increase the reactivity of the hydroxylamine allowing it to react much faster with a neighboring nitroso group.

The CV experiments using 4-NTP SAMs may suggest that the hydroxylamine once formed is unstable under the examined experimental conditions and not suitable for $\mathrm{Ab}$ immobilization. It was thought that by changing the structure of the starting nitro derivative, the longterm stability of the resulting hydroxylamine monolayer could be improved. To test this theory, monolayers of 4((4-nitrophenyl)ethynyl)benzenethiol 2 (4-NEB) and 3-((4nitrophenyl)ethynyl)thiophene 3 (3-NET) were prepared in the same manner as the 4-NTP monolayers. The positive effects anticipated from the change in structure were (1) an increased resistance to desorption given the extended length [36, 37] and (2) a decrease in the nucleophilicity of the hydroxylamine given the greater distance of the donating sulfur from the hydroxylamine. The decrease in nucleophilicity of the hydroxylamine should limit surface decay due to cross-coupling. The electrochemical reductions of both the 4-NEB and 3-NET SAMs were carried out under the same conditions as the 4-NTP monolayers. Under these conditions the 3-NET monolayer did not show any current response when the reducing potential (of $-400 \mathrm{mV}$ ) was applied for $30 \mathrm{~min}$. Poising the electrode at more negative potentials $(-450 \mathrm{mV}$ and $-500 \mathrm{mV})$ did not produce a measurable current response. It was later determined that the reducing potential of $-400 \mathrm{mV}$ was sufficient to cause $100 \%$ desorption of the 3-NET monolayer.

The 4-NEB SAM, however, does show similar redox behavior to the 4-NTP monolayers. The redox cycle between the hydroxylamine and nitroso intermediates of the 4NEB SAM is initiated by applying the reducing potential of $-400 \mathrm{mV}$ for $30 \mathrm{~min}$. Unlike the 4 -NTP monolayers, however, the reduction potential $(-400 \mathrm{mV})$ at the 4 -NEB modified electrodes can be applied for $2 \mathrm{~h}$ before a decrease in the current response was observed (Figure 4). This noted increase in current response over a longer period of time could be indicative of an increase in the stability of the hydroxylamine monolayer. The peak separation during the course of this experiment does increase from an initial value of $10 \mathrm{mV}$ to $16 \mathrm{mV}$, which may suggest that some of the monolayer is being removed from the surface. In comparison to the peak separations seen by Tsutsumi et al. [33] of $20 \mathrm{mV}$ for the 4-NTP monolayer we do not believe that a significant amount of desorption is occurring.

Also noted from these experiments is a shift in the anodic current response to $-69 \mathrm{mV}$ as compared to the anodic current response of $-100 \mathrm{mV}$ for the reduction of 4-NTP. This suggests that the reoxidation of the hydroxylamine monolayers produced from 2 is more difficult. A possible explanation for this is the extended distance of the redox active species from the electrode surface; that is, 4-NTP is shorter than 4 -NEB. This change in length is expected to have an impact on the overall distance the electrons transferred must travel to and from the electrode surface thus the increased difficulty in reoxidizing the monolayer.

Although the 4-NEB monolayers showed increases in the current response over longer periods of time as compared to the 4-NTP monolayers, Figure 5 shows that the longterm stability of the hydroxylamine monolayer is still not as desired. After applying the reducing potential for $2 \mathrm{~h}$ (the time noted for maximum current formation), the electrode was allowed to return to the open circuit potential and a CV scan was taken every $30 \mathrm{~min}$ for $6 \mathrm{~h}$. Figure 5 shows that over this six-hour period, a decrease in the current response was 


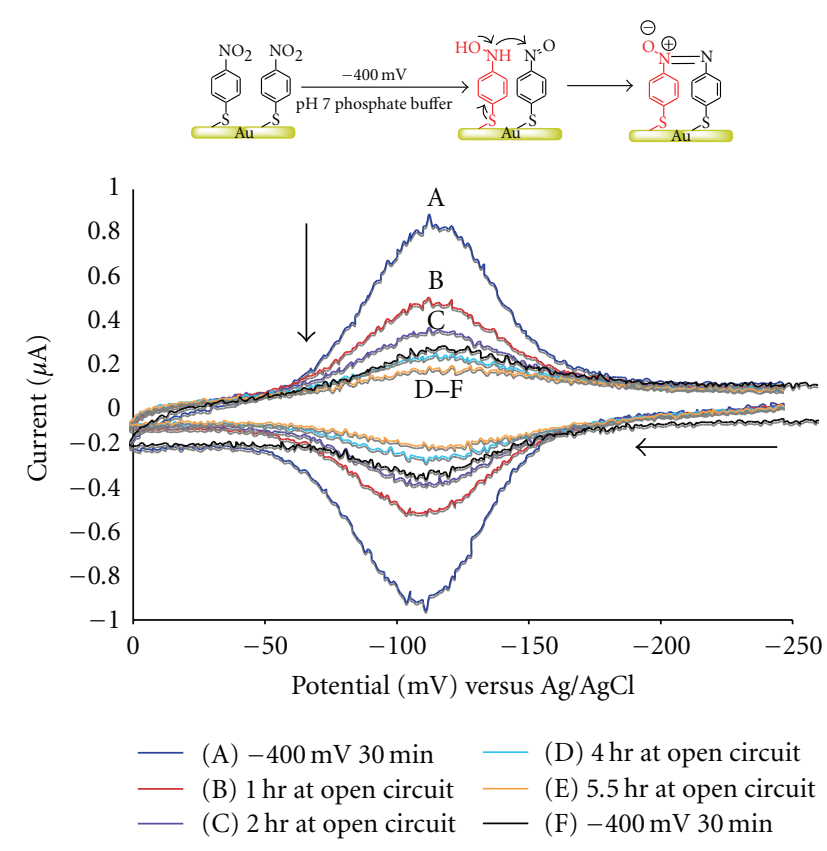

FIgURe 3: Azoxy formation at monolayer surface.

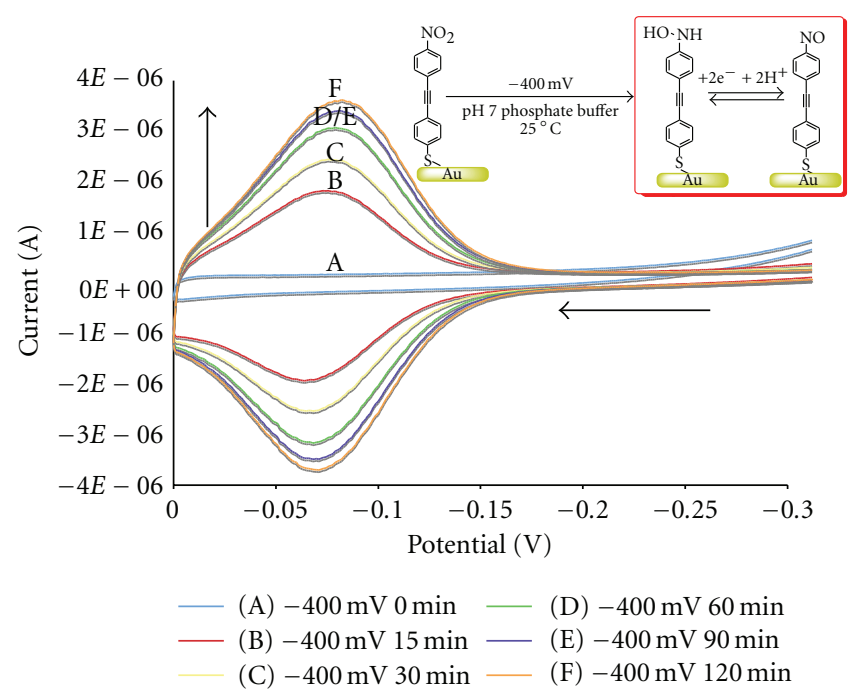

Figure 4: Hydroxylamine formation with bisphenylethynyl nitro system.

only observed over the first $90 \mathrm{~min}$. In comparing this with the previous experiments using the 4-NTP monolayers by extending the distance of the redox active functional group from the surface, the irreversible process that accounts for the loss in current response is slowed. Though the 4-NEB monolayers have an increased tolerance towards the reducing potential, the significant loss in current response while at the open circuit potential suggests that additional optimization of the surface is required to facilitate the immobilization of the $\mathrm{Ab}$ to these surfaces via reaction with the hydroxylamine.

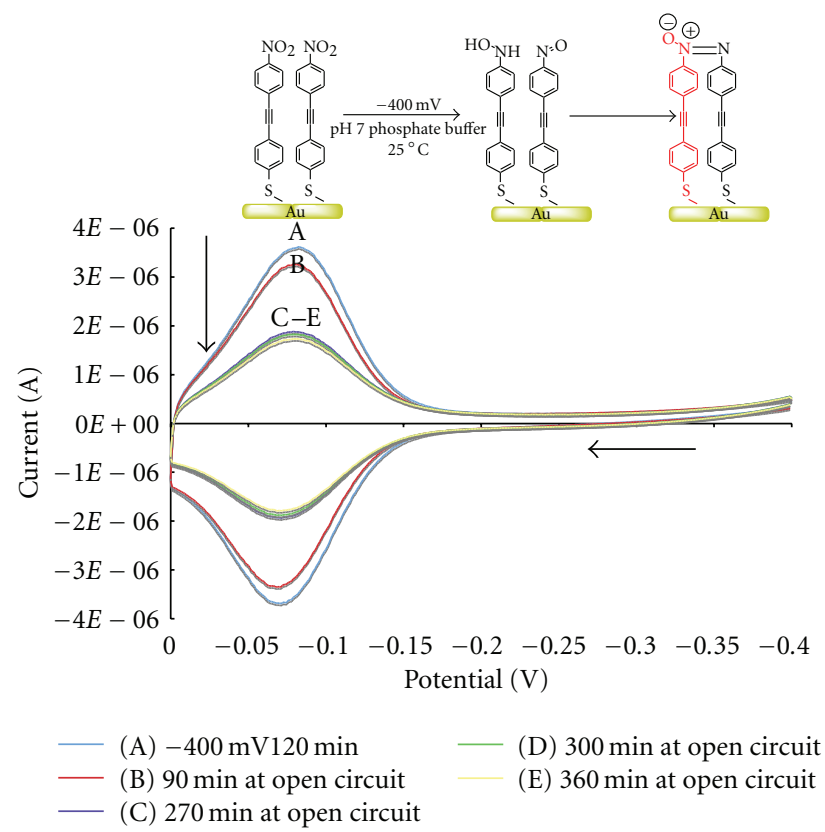

FIgURe 5: Azoxy formation using bisphenylethynyl nitro system.

\section{Conclusions}

Several strategies can be taken to make the N-arylhydroxylamine functional group useful for the immobilization of $\mathrm{Ab}$ onto electrode surfaces. A first strategy would be to synthesize a bis(phenyl)ethynyl derivative which should further increase the time that a reducing potential could be applied. This system would also help minimize any activating affects of the donating sulfur reducing the unwanted cross-coupling even further. A second strategy to help minimize the loss of current response due to cross-coupling is the use of a mixed monolayer [38]. By using a mixed monolayer approach, spacers could be placed between the reactive intermediates preventing their direct contact. Finally, the reduction of the electrode surface to generate the hydroxylamines could also be carried out in the presence of the oxidized $\mathrm{Ab}$ in an effort to react the hydroxylamine as it is generated.

In summary, several novel molecular wire-based materials were synthesized using the Sonogashira reaction as a key step. The electrochemical reduction of both 4-nitrothiophenol and 4-((4-nitrophenyl)ethynyl)benzenethiol monolayers to their corresponding hydroxylamines was accomplished. The electrochemical reduction of 4-((4nitrophenyl)ethynyl)-benzenethiol has shown that by changing the structure of the starting nitrobenzene, an increase in the concentration of hydroxyl amine at the surface can be achieved.

\section{Acknowledgments}

This work was financially supported by the Thomas and Kate Jeffress Foundation and the Department of Chemistry at Virginia Commonwealth University. The authors would also like to thank Dr. Fred Hawkridge for the use of his equipment and laboratory space. 


\section{References}

[1] J. E. Pearson, A. Gill, and P. Vadgama, "Analytical aspects of biosensors," Annals of Clinical Biochemistry, vol. 37, no. 2, pp. 119-145, 2000.

[2] H. Oyama, I. Suzuki, Y. Kato, T. Umemura, and J. Goto, "Oligosaccharide-assisted direct immunosensing of small molecules," Analytical Chemistry, vol. 82, no. 11, pp. 43334336, 2010.

[3] C. Berggren, B. Bjarnason, and G. Johansson, "Capacitive biosensors," Electroanalysis, vol. 13, no. 3, pp. 173-180, 2001.

[4] E. Mallat, D. Barceló, C. Barzen, G. Gauglitz, and R. Abuknesha, "Immunosensors for pesticide determination in natural waters," Trends in Analytical Chemistry, vol. 20, no. 3, pp. 124132, 2001.

[5] O. Lazcka, F. J. D. Campo, and F. X. Munoz, "Pathogen detection: a perspective of traditional methods and biosensors," Biosensors and Bioelectronics, vol. 22, no. 7, pp. 1205-1217, 2007.

[6] S. Rodriguez-Mozaz, M. P. Marco, M. J. Lopez de Alda, and D. Barceló, "Biosensors for environmental monitoring of endocrine disruptors: a review article," Analytical and Bioanalytical Chemistry, vol. 378, no. 3, pp. 588-598, 2004.

[7] G. G. Guilbault, B. Hock, and R. Schmid, "A piezoelectric immunobiosensor for atrazine in drinking water," Biosensors and Bioelectronics, vol. 7, no. 6, pp. 411-419, 1992.

[8] J. L. Marty, B. Leca, and T. Noguer, "Biosensors for the detection of pesticides," Analusis, vol. 26, no. 6, pp. M144M149, 1998.

[9] K. Catt, H. D. Niall, and G. W. Tregear, "Solid phase radioimmunoassay," Nature, vol. 213, no. 5078, pp. 825-827, 1967.

[10] Q. Weiping, X. Bin, W. Lei et al., "Orientation of antibodies on a 3-aminopropyltriethoxylsilane-modified silicon wafer surface," Journal of Inclusion Phenomena and Macrocyclic Chemistry, vol. 35, no. 102, pp. 419-429, 1999.

[11] B. Lu, M. R. Smyth, and R. O’Kennedy, “Oriented immobilization of antibodies and its applications in immunoassays and immunosensors," Analyst, vol. 121, no. 3, pp. 29R-32R, 1996.

[12] A. Gottschalk, Ed., Glycoproteins, Elsevier, New York, NY, USA, 1972.

[13] D. J. O'Shannessy, "Hydrazido-derivatized supports in affinity chromatography," Journal of Chromatography, vol. 510, pp. 13-21, 1990.

[14] D. J. O'Shannessy and W. L. Hoffman, "Site-directed immobilization of glycoproteins on hydrazide-containing solid supports," Biotechnology and Applied Biochemistry, vol. 9, no. 6, pp. 488-496, 1987.

[15] D. J. O'Shannessy and R. H. Quarles, "Labeling of the oligosaccharide moieties of immunoglobulins," Journal of Immunological Methods, vol. 99, no. 2, pp. 153-161, 1987.

[16] D. J. O'Shannessy and R. H. Quarles, "Specific conjugation reactions of the oligosaccharide moieties of immunoglobulins," Journal of Applied Biochemistry, vol. 7, no. 4-5, pp. 347355, 1985.

[17] C. A.C. Wolfe and D. S. Hage, "Studies on the rate and control of antibody oxidation by periodate," Analytical Biochemistry, vol. 231, no. 1, pp. 123-130, 1995.

[18] W. L. Hoffman and D. J. O'Shannessy, "Site-specific immobilization of antibodies by their oligosaccharide moieties to new hydrazide derivatized solid supports," Journal of Immunological Methods, vol. 112, no. 1, pp. 113-120, 1988.

[19] M. Wang, L. Wang, G. Wang et al., "Application of impedance spectroscopy for monitoring colloid Au-enhanced antibody immobilization and antibody-antigen reactions," Biosensors and Bioelectronics, vol. 19, no. 6, pp. 575-582, 2004.

[20] S. -Y. Dong, H. -M. Ma, X. -J. Duan, X. -Q. Chen, and J. Li, "Detection of local polarity of $\alpha$-lactalbumin by $\mathrm{N}$-terminal specific labeling with a new tailor-made fluorescent probe," Journal of Proteome Research, vol. 4, no. 1, pp. 161-166, 2005.

[21] H. Fukushima and T. Tamaki, "Molecular motion of electrically stimulated self-assembled monolayers on gold surface," Journal of Physical Chemistry B, vol. 106, no. 29, pp. 71427145, 2002.

[22] J. C. Love, L. A. Estroff, J. K. Kriebel, R. G. Nuzzo, and G. M. Whitesides, "Self-assembled monolayers of thiolates on metals as a form of nanotechnology," Chemical Reviews, vol. 105, no. 4, pp. 1103-1169, 2005.

[23] A. Ulman, "Formation and structure of self-assembled monolayers," Chemical Reviews, vol. 96, no. 4, pp. 1533-1554, 1996.

[24] A. Ulman, An Introduction to Ultrathin Organic Films from Langmuir-Blodgett to Self-Assembly, Academic Press, New York, NY, USA, 1991.

[25] O. Kamm, "Beta=Phenylhydroxylamine," in Organic Syntheses, A. H. Blatt, Ed., vol. 1, pp. 445-447, John Wiley and Sons, New York, NY, USA, 2nd edition, 1932.

[26] P. Ren, T. Dong, and S. Wu, "Synthesis of N-arylhydroxylamines by antimony-catalyzed reduction of nitroarenes," Synthetic Communications, vol. 27, no. 9, pp. 1547-1552, 1997.

[27] S. Uchida, K. Yanada, H. Yamaguchi, and H. Meguri, "Synthesis of N-Arylhydroxylamines by tellurium-catalyzed reductions of aromatic nitro compounds," Chemistry Letters, pp. 1069-1070, 1986.

[28] K. Yanada, H. Yamaguchi, H. Meguri, and S. Uchida, "Selenium-catalysed reduction of aromatic nitro compounds to N-arylhydroxylamines," Journal of the Chemical Society, Chemical Communications, no. 22, pp. 1655-1656, 1986.

[29] P. D. Ren, X. W. Pan, Q. H. Jin, and Z. P. Yao, "Reduction of nitroarenes to $\mathrm{N}$-arylhydroxylamines with $\mathrm{KBH} 4 / \mathrm{BiCl} 3$ system," Synthetic Communications, vol. 27, no. 20, pp. 34973503, 1997.

[30] N. R. Ayyangar, K. C. Brahme, U. R. Kalkote, and K. V. Srinivasan, "Facile transfer reduction of nitroarenes to $\mathrm{N}$ arylhydroxylamines with hydrazine in the presence of raney nickel," Synthesis, vol. 22, no. 3, pp. 938-941, 1984.

[31] T. Yoshioka, H. Yamada, and T. Uematsu, "Glycosides of $\mathrm{N}$-hydroxy-N-arylamine derivatives. Part 2. Convenient synthetic methods for $\mathrm{N}$-glycosides of N-hydroxy-N-arylamines," Journal of the Chemical Society, Perkin Transactions 1, pp. 1271-1276, 1985.

[32] H. Lund, "Cathodic reduction of nitro and related compounds," in Organic Electrochemistry, H. Lund and O. Hammerich, Eds., pp. 379-409, Marcel Dekker, New York, NY, USA, 4th edition, 2001.

[33] H. Tsutsumi, S. Furumoto, M. Morita, and Y. Matsuda, "Electrochemical behavior of a 4-Nitrothiophenol modified electrode prepared by the self-assembly method," Journal of Colloid And Interface Science, vol. 171, no. 2, pp. 505-511, 1995.

[34] J. U. Nielsen, M. J. Esplandiu, and D. M. Kolb, “4-nitrothiophenol SAM on Au(111) investigated by in situ STM, electrochemistry, and XPS," Langmuir, vol. 17, no. 11, pp. 3454-3459, 2001.

[35] E. Boyland and R. Nery, "Arylhydroxlamines III: reactions with aldehydes," Journal of the Chemical Society, vol. 85, no. 14, pp. 3141-3144, 1963.

[36] M. D. Porter, T. B. Bright, D. L. Allara, and C. E. D. Chidsey, "Spontaneously organized molecular assemblies. 4. Structural 
characterization of n-alkyl thiol monolayers on gold by optical ellipsometry, infrared spectroscopy, and electrochemistry," Journal of the American Chemical Society, vol. 109, no. 12, pp. 3559-3568, 1987.

[37] E. Sabatani, J. Cohen-Boulakia, M. Bruening, and I. Rubinstein, "Thioaromatic monolayers on gold: a new family of selfassembling monolayers," Langmuir, vol. 9, no. 11, pp. 29742981, 1993.

[38] H. C. W. Hays, P. A. Millner, and M. I. Prodromidis, "Development of capacitance based immunosensors on mixed selfassembled monolayers," Sensors and Actuators, B, vol. 114, no. 2, pp. 1064-1070, 2006. 

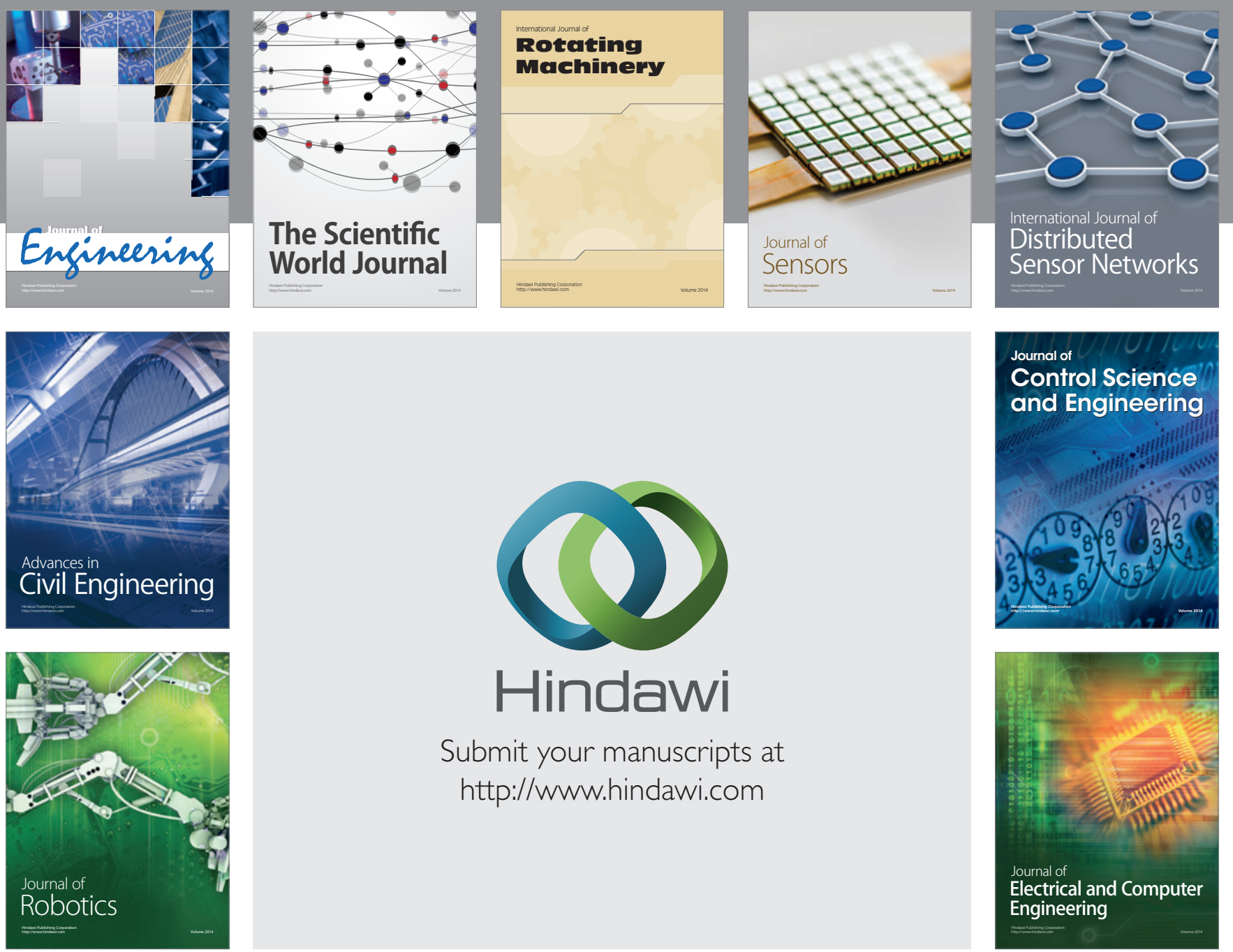

Submit your manuscripts at

http://www.hindawi.com
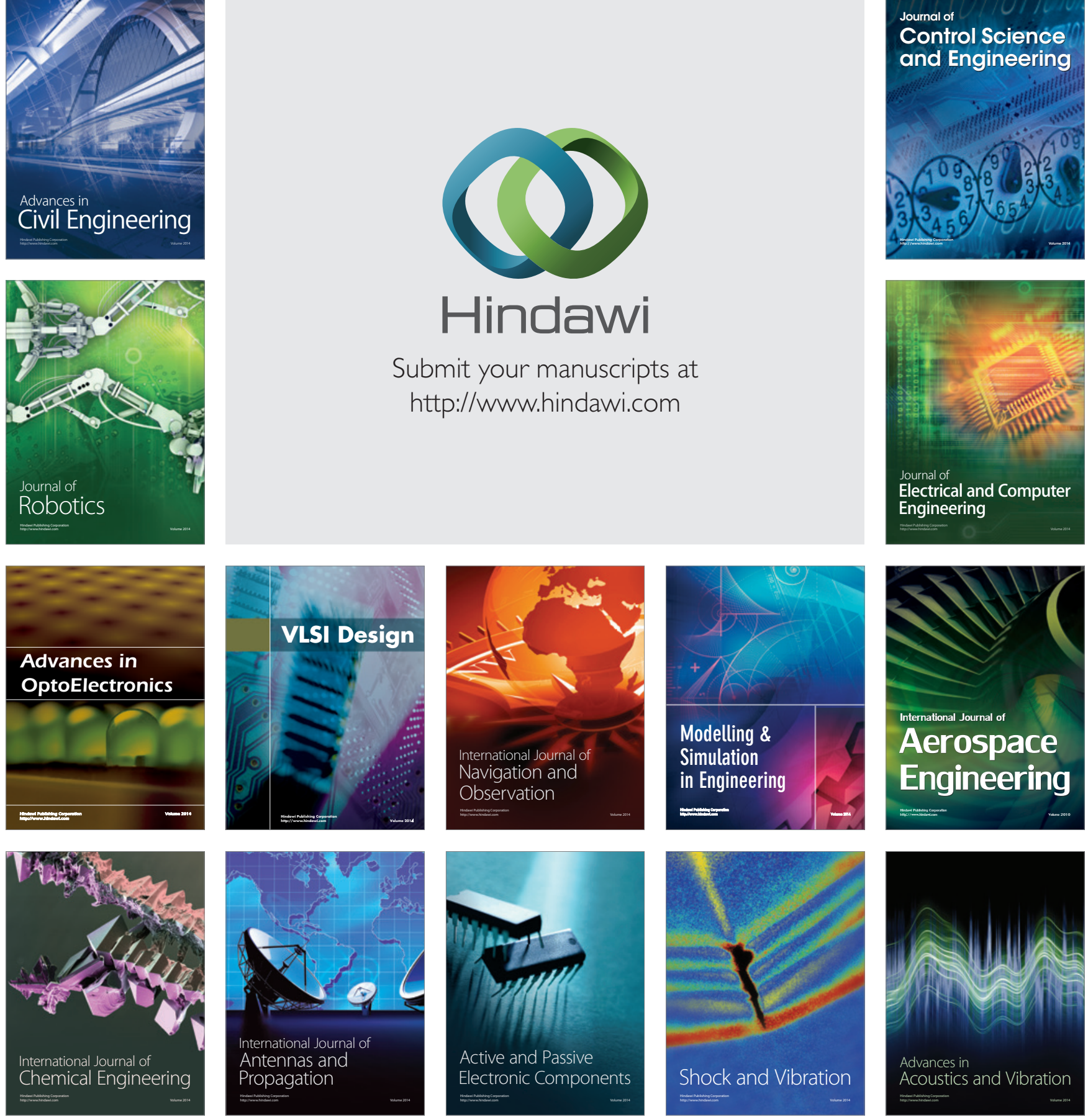